\author{
Н.Х. Орлова, С.В. Соловьев
}

\title{
Из истории логики в дореволюционной России: стратегии академического взаимодействия ${ }^{1}$
}

\author{
Орлова Надежда Хаджимерзановна \\ Институт философии, Санкт-Петербургский государственный университет \\ Российская Федерация, 199034, г. Санкт-Петербург, Менделеевская линия, д. 5 \\ e-mail: nadinor@mail.ru
}

\section{Соловьев Сергей Владимирович}

Университет Тулузы 31062, France, Toulouse 118 route de Narbonne Санкт-Петербургский национальный исследовательский университет информационных технологий, механики и оптики Российская Федерация, 197101, г. Санкт-Петербург, Кронверкский пр., д. 49 e-mail: soloviev@irit.fr

В статье рассматриваются вопросы становления логики и развития логических исследований в дореволюционной России с точки зрения коммуникации внутри российского академического сообщества. Реконструируются в исторической ретроспективе своеобразный канон организации учебной литературы по логике, появление традиции ссылок на отечественных специалистов, практика написания своеобразных критических «книг-ответов» на труды коллег по цеху. Рассматриваются различные виды публикационной активности (переводы, учебники, авторские книги). Для российских логиков страницы книг были площадкой для ведения научной полемики, научного обмена, в том числе и с международным научным сообществом. Показан взаимообмен и эмансипация логики в отношениях с другими науками, такими как психология и математика, в том числе влияние на развитие российской логики так называемой революции в основаниях математики. В ходе исследования привлекаются многочисленные источники, не переиздававшиеся со времени оригинальной публикации.

Ключевые слова: история логики, математика, академическое сообщество, стратегии коммуникации, публикационная активность, цитирование

\footnotetext{
${ }^{1}$ Работа выполнена в рамках совместного научного семинара «Социальная история логики: научный и историко-культурный аспект» (IRIT Университет Тулуза-СПбГУ, 2015) и сотрудничества между Университетом Тулузы и университетом ИТМО в С.-Петербурге (при поддержке гранта РФ 074-U01).
} 
Обращение к прошлому плодотворный источник познания настоящего. Морис Клайн [18, с. 8]

Об истории логики в дореволюционной России писали, хотя и не очень много. Из монографий, касающихся этой темы, упомянем, например, работы Маковельского [31] и Бажанова [3]. Укажем также на замечательный биобиблиографический справочник «Логика» [25], составители которого решали задачу обобщить данные по отечественным ученым, которые в своей научной деятельности так или иначе затрагивали проблемы логики. Настоящей статьей авторы ставят перед собой задачу актуализации темы в контексте стратегий коммуникации внутри российского научного сообщества ${ }^{2}$, а также его взаимодействия с сообществом международным. С учетом этой задачи складывается условная периодизация, вводятся в оборот источники, незаслуженно, на наш взгляд, исключенные из исследовательского корпуса источников по данной проблеме, приводятся примеры острых дискуссий и комплиментов на полях научных изданий. Это позволяет реконструировать социальную историю становления логики как самостоятельного направления научного знания на русской почве, пафосом которого является фигура ученого, встроенного в сложные каноны, разрешительные и запретительные системы научной коммуникации.

Конечно, предварительным условием для содержательного рассмотрения является общее понимание процессов (хотя бы на уровне предварительного очерка), происходивших в научной и интеллектуальной жизни Российской Империи, в той мере, в какой они связаны со становлением логики как науки. Периодизация необходима как некоторое организующее начало. Основанием для нее вполне оправданно считать эпоху петровских реформ, так же как и революцию 1917 года, которые были переломными в истории страны. Менялось

\footnotetext{
${ }^{2} \mathrm{~B}$ разные эпохи это понятие, очевидно, обладает разным наполнением, но его вариативность скорее подчеркивает важность коммуникативных аспектов, о которых пойдет речь.
} 
место науки в жизни общества. Оговоримся сразу, что в данной статье решено было сосредоточиться именно на дореволюционном периоде, без которого трудно говорить о последующем, не выделяя, однако, особо допетровскую эпоху. В дальнейшем авторы планируют рассмотреть историю становления науки логики в том же аспекте взаимодействия и стратегий коммуникации в среде ученых логиков советского времени.

О каких-либо самостоятельных научных идеях в области логики в России до XIX в. говорить сложно. Однако не следует и упрощенно оценивать то, как складывалась традиция приобщения русского ученого к общемировой, как мы бы сегодня сказали, базе источников даже в такой узкоспециальной области, как логика.

K первым логическим текстам, которые были известны еще в Древней Руси (сошлемся здесь на указанные выше работы $[3,25,31]$ ), относят некоторые статьи Изборника 1073 г., а также «Диалектику» Иоанна Дамаскина. Ее славянский перевод появился в X в. В XV в. становятся доступными первые переводы на русский язык некоторых логических сочинений: «Книга глаголемая логика» (выдержки из сочинений Моисея Маймонида) и «Логика Авиасафа» (аналогичные выдержки из сочинений Аль-Газали). Как полагают исследователи, они были переведены, скорее всего «новгородско-московскими еретиками-жидовствующими».

Вплоть до XIX в. логические сочинения, доступные на русском языке, за немногими исключениями, оставались переводными. K исключениям относится «Сказ о логике», написанный князем Андреем Курбским. Он же был и автором нового перевода «Диалектики» Иоанна Дамаскина. Его перевод «От другие диалектики Иоанна Спанъинбергера о силлогизме вытолкована» (Вильно, 1586) был первой печатной книгой на русском языке по логике [25].

Россия вовсе не была пассивным рецепиентом идущих извне информационных потоков. Отбор текстов для перевода требовал активного, обращенного вовне интереса и ознакомления с источниками. Меняющийся политический ареал Московского царства, а в дальнейшем Российской Империи способствовал тому, что в обороте находились многочисленные иноязычные тексты. В Московской 
славяно-греко-латинской академии (с 1687 г.) и в Киевской духовной академии (с 1701 г.) логика преподавалась на латинском языке. Сохранились рукописи, по которым читались эти курсы [31, с. 436].

Из наиболее значимых влияний, имеющих отношение к логике, упомянем Лейбница (1646-1716). Как известно, он переписывался с Петром I и даже встречался с ним незадолго до своей смерти. Эти контакты оказали существенное влияние на создание СанктПетербургской Академии Наук [2]. Начиная с этого времени российская наука неотделима от западноевропейской. Создание Академии(указом от 28 января (8 февраля) 1724 г.) привлекает в Россию многочисленных иностранных ученых. Заметим, что латинский язык долгое время остается основным рабочим языком академиков. Впрочем и немецкий язык также играл в работе Академии значительную роль. Вместе с тем петровские реформы положили начало гораздо более интенсивной переводческой деятельности, и логические тексты становятся более доступными в переводах.

Большую роль во взаимодействии с мировым научным сообществом играли и поездки российских студентов в западные университеты. Проявлявшие способности к научной деятельности нередко обучались там, в том числе и за государственный счет. Российские студенты, выезжавшие для обучения в Западную Европу на протяжении XVIII-XIX вв., в значительной своей части специализировались в философии ${ }^{3}$. Логика, разумеется, занимала важное место в курсах философии того периода.

\footnotetext{
${ }^{3}$ По данным А. Ю. Андреева (результаты изучения матрикулов немецких университетов), в период 1698-1849 гг. в Германии обучалось 926 русских студентов, хотя и «не сопоставимо со студенческим потоком из Прибалтики, исчисляющимся многими тысячами человек, но тем не менее, значительно, особенно в сопоставлении с посещаемостью российской высшей школы в тот же период - можно заметить, что, скажем, общее количество студентов, учившихся в Московском университете за XVIII век, примерно соответствует числу студентов той же эпохи за границей» $[1$, с. 22]. Андреев также пишет: «С.С. Уваров был вынужден издать циркуляр, запрещавший дальнейшие поездки для учебы за границу. Тем не менее, уже спустя девять лет, с 1857 г. командировки в немецкие университеты развернулись с новой силой, что свидетельствовало об объективном единстве российского и европейского научных пространств, совместное развитие которых продолжилось во второй половине XIX века» [1, с. 227].
} 
C петровского периода складывается устойчивая традиция включать изучение основ логики в учебные программы с подготовкой под эти задачи учебников. На примере учебников интересно проследить, как логика оказывается включенной в сложную сеть общественных и научных связей, порой неожиданных.

Поначалу авторский вклад русских ученых ограничивался переводом и наставительным обращением к читателю ${ }^{4}$. Например, учебник, подготовленный магистром Сергеем Андриановским, предваряется словами: «Недостаток учебных книг сходственных с вашим любезные Российские Юноши! понятием возбудил меня перевесть на Российский язык кратчайшую сию Логику» ${ }^{5}$. И здесь же о пользе для сомневающихся: «. . скажи, что она приводит человеческий разум в порядок, научает правильно и основательно рассуждать: то найдутся такие, которые сему не поверят, или за важное сие не почтут» $[19$, с. 1-2]. Подчеркивается и значение изучения логики на русском языке. Из обращения к читателю в «Детской логике...»: «История свидетельствует, что во всех почти народах тогда начали процветать науки, когда их стали учить, и учиться на своих природных языках» [13, с. 3].

Другой пример «обязательной» общественной привязки. Для любого печатного издания обязательным было подробное указание на цензурное «одобрение», которое часто было персонифицировано. Так, «Детская логика...» подписана «Коллежским Советником Красноречия Профессором и Цензором печатаемых в Университетской Типографии книг Антоном Барсовым». Дословно: «По приказанию Императорского Московского Университета Господ Кураторов я читал книжку под заглавием «Детская логика, сочиненная для употребления российского юношества», и не нашел в ней ничего противного наставлению, данному мне о рассматривании печатаемых в

\footnotetext{
${ }^{4}$ Авторство зачастую устанавливается лишь по дополнительным источникам. См., напр., [34]. Автор Феоктист [Мочульский, Иван (1732-1818)] установлен по изд. Русский биографический словарь. В предисловии издателей: «Дар учителю»: лейб-гвардии конного полку вахмистры Иван Болъший, Иван Менъший Мочульские.

5 Здесь и далее мы сохраняем орфографию согласно написанию в цитируемом источнике.
} 
Университетской Типографии книг; почему оная и напечатана быть может» [13].

Значимость учебников подчеркивалась и благодарственным обращением в адрес персон, поддержавших проект. Порой именно обращение позволяет нам сегодня знать о вкладе переводчика или составителя. Так мы узнаем и имя Андриановского, подписавшего обращение с благодарностью к «Его Превосходительству, Московского Университета г. директору Павлу Ивановичу Фон-Визину Действительному Штатскому Советнику и Св. Равно-Апостольного Князя Владимира третьей степени Кавалеру». Большинство учебников придерживаются определенного канона, что порой обосновывает отсутствие «присутствия» имени составителя 6 .

Ссылочный аппарат учебников традиционно отсылает к известным текстам европейских ученых («Логике» Баумейстера (1760), Вольфа (1765) и др.). Русские имена в них практически не встречаются. «Умословие. . » Ивана Рижского хорошо иллюстрирует эту традицию. Уточняется логика систематизации материала и основные источники: «...большая часть правил и размышлений почерпнуты из Философских сочинений г. Голльмана; немало из других известнейших Писателей сего рода; прочее же единственно из природного Умословия» $[41$, с. 1]. Об этой работе можно говорить как об опыте написания уже аналитического текста. Во вступлении дается определение философии, уточняется ее предмет («усовершенствование двух главных человеческих способностей, то есть, разума и воли»). В корпусе философских направлений умословие (Logica) «наставляет наш разум доходить до справедливого познания» [41, с. 4]. Дается систематизированная классификация: Logica naturalis (умословие природное) связывается с Баумейстеровой элементарной логикой (природной способностью познавать, рассуждать) и Вольфиевой логикой (способностью упражняться в познании истины); Logica artificialis (умословие искусственное) или Philosophia rationalis (ум-

\footnotetext{
${ }^{6}$ См., напр.: [46]. Автор перевода не указан. Весьма объемный, по числу страниц, учебник соответствует сложившемуся на то время «стандарту» содержания разделов: О Логике вообще, О началах логических, О Представлении; О Предложении; О Умствовании; О Методе и способе.
} 
ственная философия) связываются с Голльманновой логикой. Тезисы автора сопровождаются ссылками на Платона, Аристотеля, письма Эйлера и др. Оглавление дает представление о категориальном и содержательном насыщении, которое предполагается в изучении логики, и о весьма высоком уровне требований к познанию ее основ ${ }^{7}$.

Взаимосвязи внутри логического сообщества, о которых свидетельствуют взаимные ссылки, постепенно усиливаются к концу XIX столетия. И учебники, и курсы лекций теперь, как правило, отсылают не только к привычному корпусу работ европейских логиков, но и к отечественным именам. Так, вышедший в конце XIX в. «Учебник логики...» [45] профессора Московского университета М.M. Троицкого (1835-1899) цитирует уже многие имена отечественных авторов. Перечисление показывает, насколько расширилось научное сообщество к этому времени. Упоминаются имена Н.В. Бугаева (1837-1903) [7], В.Н. Карпова (1798-1867) [17], В.В. Лесевича (18371905), П.Д. Лодия (1764-1829) [28], О.М. Новицкого (1806-1881) [36], А.И. Райковского (1802-1860) [40], А.Е. Светилина (1841-1887 )[43] и др. [45, с. 12].

Теперь уже сочинения по логике выходят как минимум в формате «связного обозрения», часто с серьезными самостоятельными идеями. «Обычай отдельного связного обозрения всех аксиом логики» в русской литературе устанавливается «еще с сороковых годов, или с логических сочинений Новицкого и Пащенко» [45, с. 86].

Публикуются лекции, иногда записанные и подготовленные в печать студентами, иногда литографированные авторские рукописи, как в случае с «Историей логики» П. Каптерева (1849-1922) [15]. В его лекциях, наряду с каноническими отсылками к Аристотелю, уделяется особое внимание популярной тогда проблеме различения

\footnotetext{
${ }^{7}$ См., напр.: «Часть первая: О действиях разума, О понятиях, О словах и терминах, Об определениях и разделениях, О рассуждениях и предложениях, Об умствованиях и силлогизмах. О сложных и неправильных силлогизмах; Часть вторая: Об истине вообще, О признаках истины, О началах истины, О познании истины, О погрешностях; Часть третья: О правильном употреблении понятий и рассуждений, О правильном употреблении умствования и силлогизмов, О заимствовании познания от современников, чтении книг, О сообщении своего познания другим» [41].
} 
задач и предмета психологии и логики, имея в виду, что обе науки занимаются мышлением, мыслительной деятельностью. Фиксируются два основных вектора развития: «логики силлогистической или дедуктивной и логики индуктивной, иначе первая называется логикой формальною, а вторая - реальною» [15, с. 2]. Подчеркивается значение и влияние системы Аристотеля на «средневековую логику», задача которой состояла в том, чтобы «указать все возможные виды логических форм и в частности условного силлогизма» [15, с. 6]. Кант, Гербарт оказывают огромное влияние на историю развития логики, понимая ее «как науку чисто формальную». И «в наших русских логиках (Светилин, Дитигис, Струве) сказывается этот формальный элемент». Анализируются попытки создания третьего направления развития логики, которое сосредоточивает свои усилия на том, чтобы «соединить в одно целое первые два». Из русских логиков этого направления Каптерев рекомендует профессора Владиславлева, книга которого написана «сравнительно живо и достаточно доступна» [15, с. 10-11].

Работы, посвященные критическому разбору работ коллег по цеху, дают яркое представление о том, что в отечественной традиции такой «цех» сложился, а также об авторитетах и основных дискуссиях. Примером может служить очерк Е.А. Боброва (1867-1933) [4] о И.И. Ягодинском (1869) [48], который «успел зарекомендовать себя, как один из наилучших у нас знатоков Лейбница» и к изучению монадологии которого он «идет новым путём, а именно: идет со стороны изучения его гигантской переписки, которая $<\ldots>$ часто дает ключ к пониманию системы Лейбница в гораздо большей степени, чем сами его сочинения, опубликованные им при жизни» [4, с. 62].

Значительная часть очерка посвящена тезисному пересказу основных положений работы Ягодинского. Есть несколько обобщающих аналитических суждений, которые уточняют позицию самого автора. «Реформаторы $<\ldots>$ не отдают подобающей чести логике Стагирита. Они считают ее окончательно ниспровергнутой. Между тем Аристотелева логика, конечно, не искаженная, школьная, а подлинная, реставрированная в ее настоящем виде, на наш взгляд, далеко еще не преодолена - и с нею необходимо считаться, как нельзя 
до сих пор игнорировать и ее метафизические основания - универсализм или идеализм» [4, с. 77].

В целом отмечается, что книга Ягодинского «по своим основным идеям оригинальная и новая». $\mathrm{K}$ чести автора «служит его постоянное стремление выдвигать работь и идеи наших русских ученых логииистов [курсив наш. - Н.О., С.C.], подчас не лишенные оригинальности и ценности, но либо забытые, либо на себя не обратившие достодолжного внимания, а для западных ученых оставшихся и совсем неизвестными» [4, с. 79]. Бобров уверен, что если бы книга вышла на немецком языке, то в обширной немецкой философии она не осталась бы незамеченной. «В нашей же небогатой, чтобы не сказать прямо: скудной - оригинальной философской литературе книга Ягодинского представляет собой отрадное явление и ценный вклад» $[4$, с. 80].

Развернутый корпус работ, на которые ссылается Ягодинский, дает нам энциклопедическое представление об именах русских ученых, создававших традицию изучения логики в России того времени. Приведем часть «списка»: Е.А. Бобров [5], А.И. Введенский (18561925) [10], М.И. Владиславлев (1840-1890) [11], Н.Я. Грот (18521899) [12], Ф.А. Зеленогорский (1839-1908), М.И. Каринский (1840 1917) [16], Н.Н. Ланге (1858-1921) [20], П.Э. Лейкфельд (1859-193?) [22], Н.О. Лосский (1870-1965)[29], [30], П.С. Порецкий (1846-1908) [37],[38], Э.Л. Радлов (1854-1928) [39], Л.В. Рутковский (1859-1920) [42], Г.Е. Струве (1840-1912) [44], Г.И. Челпанов (1862-1936) [47].

Работа Ягодинского этим блестящим «парадом ссылок» отличается от большинства публикаций его современников, в которых не находим традицию ссылаться на российских коллег по цеху. Например, крупный логик профессор Каринский пишет о поисках оптимальных логических систем в истории становления логики как науки, отсылая к ее аристотелевскому началу. Два основных вектора: формальный и индуктивный провоцировали попытки их объединить на том основании, что «мысль человеческая собственно только одна, только в одном случае она имеет дело с фактами, а в другом с аксиомами, но мыслительный процесс сходен в обоих случаях» [16, с. 11]. Перечисляя, однако, авторитеты в истории развития логики, Карин- 
ский по отношению к отечественным ученым, пишет: «... а также и несколько русских», - не приводя ни одного имени.

K началу XX в. складывается канон подготовки учебников логики не в технике банальных переводов, пусть и с комментариями, но именно написания аналитических трудов, учитывающих как западную традицию, так и русскую. Исторический метод остается доминирующим как своего рода стратегия, позволяющая становиться логике в условиях научных переворотов и сомнений. Например, Е.А. Бобров поясняет, что по его глубокому убеждению, «вынесенному из многолетнего преподавания логики в университетах, одна только историческая школа может дать начинающему твердую и объективную почву для дальнейших благотворительных занятий логикою - ввиду крайнего смутного и спорного положения, какое наука логики (если ее вообще считать специальною наукой!) занимает именно в наши дни» $[5, \text { с. } 1]^{8}$.

В наши задачи не входил детальный анализ работы Боброва, тем более что сам по себе он представляет привычный разбор системы логики Аристотеля. Отметим лишь появление новых акцентов, подчеркивающих взаимоотношения математики и логики ${ }^{9}$. Подчеркивается важность открытия логических законов тождества и противоречия для математики, которые «гарантируют ей сам характер науки. Математика считается наиболее точной и правильной наукой, но она вместе с тем ничуть не заботится, существует ли, в самом деле, - во внешнем мире то, что составляет предмет ее исследований (например, точки, линии); напротив того, она совершенно спокойно оперирует над чисто умственными и абстрактными предметами» $[5$, с. 80]. Основной упрек к математике в том, что ее «правильность»

\footnotetext{
${ }^{8}$ В Российской национальной библиотеке (Санкт-Петербург) хранится издание с личным автографом «Дорогому и добрейшему Григорию Васильевичу Левицкому». Заметим, что дарственный автограф «Дорогому Григорию Васильевичу Левицкому на добрую память, автор» есть и на экземпляре критического разбора объемной работы Ягодинского «Генетическая логика», ссылки на которую мы уже приводили. На автографы обращаем внимание в смысле подчеркивания, что российские логики читали работы друг друга, полемизировали.

${ }^{9} \mathrm{~B}$ этот период набирает силу традиция подготовки учебников для изучения математической логики. См., например: [6].
} 
обусловливается лишь тем, что помимо критерия «материального», она предлагает критерий «формальной истины». Заканчивается книга словами: «Любопытнейшим явлением в истории логики после Декарта является логика Лейбница, пытающаяся воссоединить и примирить - и старую логику Аристотеля, и новую логику Декарта и даже те некоторые оригинальные мысли о логике, которые были высказаны схоластиками. Обозрением Лейбницевой логики займется вторая часть этой книги, если этой второй части вообще суждено будет когда-либо явиться в свет...» [5, с.138]. По нашим данным, вторая часть в печати не выходила.

$$
* * *
$$

Аспект, к которому мы теперь подошли, - это роль дискуссии в становлении и, если так можно выразиться, самоосознании науки. Для логики в этот период наиболее важную роль сыграли дискуссии, связанные с начавшейся в XIX в. революцией в основаниях математики, переходящей к началу ХХ в. в так называемый «кризис оснований». Логике предстояло сыграть в нем одну из главных ролей и самой претерпеть радикальные изменения. Степень интегрированности логики в общенаучное интеллектуальное сообщество была к этому времени весьма велика, и специалисты по логике, разумеется, не могли игнорировать процессы в смежных областях науки. Очевидно, что на развитие коммуникативных стратегий в академическом сообществе влияли и бурные общественные сломы, которые лихорадили Европу. Парадоксально, но в середине XIX в. для логики на русской почве должны были наступить не самые худшие времена согласно распоряжению от 1850 г. «О прекращении преподавания в университетах философии и замене этого предмета двумя дисциплинами логикой и психологией» [35, с. 258].

Вместе с тем, по справедливому замечанию В.А. Бажанова: «В логической мысли России ХІХ - начала XX века $<\ldots>$ доминировали психологизм (и своего рода антропологизм), согласно которым логика должна заниматься анализом «реального» мышления, а не изучением последствий нормативного характера логических законов и соответствующих им принудительных конструкций. <..> 
В принципе такого рода установки тормозили развитие логики в ее математической форме» [26, с. 10].

Вплоть до XX в. преподавание математики основывалось в основном на книгах Евклида, изложение «по Евклиду» считалось образцом логической строгости. Одним из знаковых событий того времени, приведших к революции в математике, было открытие альтернативных неевклидовых геометрий в начале XIX в. Это открытие не могло не отразиться и на логике, поначалу косвенно, хотя бы в том, что касается сомнений в самоочевидности и непреложности аксиом $^{10}$.

Логика до начала этого периода тоже мало менялась со времен Аристотеля. Выше мы цитировали мнение М. Каринского в защиту аристотелевской традиции. В 1911 г. Н.А. Васильев (1880-1940), представитель младшего поколения логиков, говорил в своих лекциях в Казанском университете (цитируем по недавно опубликованному конспекту его лекций): «Вплоть до XIX века логика сохраняла в существенном все положения аристотелевской логики. $<\ldots>$ В XIX веке началась эмансипация логики от Аристотеля. Главными этапами этого движения были: метафизическая логика Гегеля, открытие Миллем законов научной индукции и его критика силлогизма, критика учения о модальности суждения, сделанная Зигвартом <..> наконец, создание математической логики трудами Буля, Шредера и Порецкого» 8 , с. 126]. Важно отметить, что начало перевороту в основаниях математики положили труды как российских, так и иностранных ученых.

Российская наука в конце XIX в. теснейшим образом связана с западноевропейской. Зачастую научные работы пишутся на иностранных языках, иностранный мог быть и языком первой публикации. Именно к таким своим публикациям отсылает П.С. Порецкий в своей статье «Из области математической логики» [37], цель которой - «познакомить читателя на простом и всем известном при-

\footnotetext{
${ }^{10}$ Как писал в 1912 г. российский логик Н.А. Васильев: «Воображаемая логика построена методом воображаемой геометрии... Для этого мне пришлось изучить неевклидову геометрию. . Из всех систем неевклидовой геометрии я более пристально занимался геометрией Лобачевского». Цит. по [27, с. 377].
} 
мере с основаниями метода математической логики и с его преимуществом перед методом отвлеченного умозрения» [37, с. 1]. Так, о разделении причин на простые и сложные и о связи между ними можно прочесть в работе «Quelques lois ultérieures de la théorie des égalités logiques» [53]; правила, на основании которых выводятся заключения, выраженные «при помощи терминов, чуждых речи, т. е. отличных от a, b, с», изложены в работе «Sept lois fondamentales de la théorie des égalités logiques» [54] (обе опубликованы в Казани); таблица, дающая без вычислений все 7424 заключения («с различными избытками») в качестве приложения приведена в статье «Théorie des égalités logiques à trois termes a, b, c» [55]; общий способ составления подобного рода таблиц для любой логической задачи о двух терминах изложен в статье «Exposé élémentaire de la théorie des égalités logiques à deux termes a et b» [56] (обе опубликованы в Париже).

Дело не только в желании познакомить иностранных ученых со своими достижениями, но и в формах влияния научных сообществ друг на друга. Нередко так называемый «непрямой» путь, по которому движутся научные идеи, надежнее всего способствует их признанию. В этом смысле поучительной является история появления и последующего признания работ Н.И. Лобачевского (1792-1856).

Сосредоточимся на главном, с точки зрения рассматриваемых в данной статье аспектов научного взаимодействия. Текст первой работы Лобачевского о пятом постулате и основаниях геометрии под заглавием «Exposition succinte des principes de la géométrie avec une démonstration rigoureuse du théorème des parallèles» был написан на французском языке [23, с. 12], [24, с. 7]. Вопрос, как именно этот текст был представлен, в виде доклада или рукописи для прочтения [24], не имеет для нас принципиального значения. Позже (в 1829 1830 гг.) он был опубликовал в журнале «Казанский вестник» под названием «О началах геометрии» (на русском языке). В 1835-1836 гг. в «Ученых записках» Казанского университета, тоже на русском, публикуется «Воображаемая геометрия» и ее продолжение «Применение воображаемой геометрии к некоторым интегралам».

Там же в 1835-1838 г. он печатает «Новые начала геометрии с полной теорией параллельных» (около 400 страниц). Как пишет 
В.Ф. Каган: «неевклидова геометрия изложена здесь более обстоятельно и понятно, чем в предыдущих работах. Но для того, чтобы дойти до главы VII, где изложение ее начинается, нужно было затратить утомительный труд на прочтение первых шести глав» [23, с. 17]. В России реакция на эти публикации Лобачевского была в то время резко критической, без особых попыток разобраться. Известно, что пользовавшийся в то время большим влиянием петербургский математик М.В. Остроградский (1801-1861) и окружавшие его математики «были предубеждены против всего, что выходило из-под пера Лобачевского» [23, с. 17]. Причины враждебности (только отчасти связанные с сутью открытий Лобачевского) рассматриваются в [24], но эти нюансы не меняют общей картины.

С целью привлечь внимание к своим исследованиям Лобачевский опубликовал краткое изложение своих теорий на немецком языке [51]. В одном из писем к коллегам Гаусс писал: «Я начинаю читать по-русски довольно успешно и нахожу в этом большое удовольствие. Г-н Кнорре прислал мне небольшой мемуар Лобачевского (в Казани), написанный по-русски, и как этот мемуар, так и небольшая книжка о параллельных на немецком языке (о ней появилась совершенно нелепая заметка в «Реперториуме» Герсдорфа) возбудили во мне желание узнать об этом остроумном (geistreich) математике» [23, с. 19].

С точки зрения проблем научной коммуникации интересно отметить, что Гаусс, по-видимому, начал изучать русский язык еще до знакомства с работами Лобачевского. Э. Кнорр (или Кнорре), упоминаемый в этом письме, - профессор Казанского университета, который «по Высочайше утвержденному положению г.г. Министров был отправлен на 9 месяцев путешествовать» и, в частности, встречался с Гауссом. Гаусс способствовал избранию Лобачевского член-корреспондентом Королевского Геттингенского общества $[24$, с. $9-10]$.

Посмертная публикация переписки Гаусса привлекла внимание западной научной общественности к работам Лобачевского. Важную роль сыграла и публикация [51]. В 1866 г. «Geometrische Untersuchungen» были переведены на французский язык. Издатель- 
ство Gautier-Villars издало его отдельной книгой. В Германии в 1887 г. переиздается издание 1840 г., а чуть позже, в 1891 г., публикуется и английский перевод в Техасском Университете в Остине.

В России, не без влияния Гаусса, приходит интерес к открытиям Лобачевского. В 1868 г. в III томе журнала «Математический Сборник» публикуется статья «О теории параллельных линий Н.И. Лобачевского». Именно эта небольшая статья становится событием, суть которого «первое, очень осторожное, признание работ Лобачевского в России» [23, с. 20]. За собственным текстом автора следует «Извлечение из переписки Гаусса с Шумахером» и перевод «Geometrische Untersuchungen». А в 1886 г. Казанским университетом издается второй том «Полного собрания сочинений по геометрии Н.И. Лобачевского», где в том числе содержались сочинения, опубликованные ранее на иностранных языках [23, с. 21]. K слову сказать, одним из первых пропагандистов идей Лобачевского в России был казанский профессор математики А.В. Васильев, отец логика Н.А. Васильева. Заметим, что «извилистость» пути к признанию характерна не только для России [14]. Интересно, например, что тот же К.Ф. Гаусс, один из наиболее выдающихся математиков того времени, сам размышлявший над идеями неевклидовой геометрии, вообще не решился их публиковать в Германии.

$\mathrm{K}$ концу XIX в. все большую роль в жизни мирового научного сообщества приобретают научные конференции и конгрессы. Для логики и логиков важную роль играют такие события международной научной жизни, как международные философские конгрессы и международные конгрессы математиков. Еще в 1893 г. математики впервые собрались на Математический Конгресс в Чикаго. В его трудах была опубликована статья И.М. Первушина (1827-1900), представленная Казанским университетом [52]. Однако Чикагский конгресс принято рассматривать отдельно от последущих международных конгрессов математиков. Он не был созван международным математическим союзом, и международное присутствие было слабым.

Собственно первый международный конгресс математиков состоялся в Цюрихе в августе 1897 г. [60]. Среди организаторов мы видим имя А.А. Маркова (1856-1922; академик, специалист по теории 
вероятностей, автор понятия «марковские цепи», отец известного в будущем советского логика, тоже А.А. Маркова). В цюрихском конгрессе приняли участие 208 математиков, из них 12 представляли Россию.

C пленарными докладами выступали такие крупные математики, как А. Пуанкаре, Ф. Клейн, Дж. Пеано (G. Peano: «Logica matematica»). Среди секционных докладов упомянем доклады Бурали-Форти (С. Burali-Forti: «Les postulats pour la géométrie d'Euclide et de Lobatschewsky»), И.М. Первушина (его зачитал А.В. Васильев: Formules pour la détermination approximative des nombres premiers, de leur somme et de leur différence d'après le numéro de ces nombres. Note adressée au Congrès par M. J[ean]. Pervouchine et traduite par M.A. Vassilief. ), Н.В. Бугаева (N. Bougaïev. «Les mathématiques et la conception du monde au point de vue de la philosophie scientifique»), Н.Е. ЖКуковского (1847-1921) [60].

В августе 1900 г. в Париже состоялись Первый Международный Философский Конгресс [57] и непосредственно после него Второй Международный Конгресс Математиков [50]. Оба конгресса были тесно связаны, в том числе и по составу докладчиков. Одним из главных организаторов философского конгресса был известный французский логик Л. Кутюра (Louis Couturat), который представлял на конгрессе доклад П.С. Порецкого (см. [57]). Среди участников находим имена В.Н. Ивановского (1867-1939), Б.Н. Чичерина (18281904), А.В. Васильева (1853-1929). В конгрессе принимали участие известные математики и философы А. Пуанкаре, Дж. Пеано, Б. Рассел, А. Бергсон.

Общее число участников Второго Международного Конгресса Математиков 248. Интересен список участников, представлявших Российскую империю [50, p. 58-115]: И.В. Мещерский (1859-1935), И.Л. Пташицкий (1854-1912), О. Сабинина (1833-1909), В.И. Шифф (1860-1919), Д.Ф. Селиванов (1855-1932), Д. Синцов (1864-1946), Г. Суслов (1857-1935), М. Тихомандрицкий (1844-1921), А.В. Васильев, Н. Забудский (1853-1917). Одним из пленарных докладчиков был Давид Гильберт, который представил свой знаменитый список из 23 открытых проблем. 
Дискуссии вокруг оснований математики, теории множеств, обнаружение парадоксов, таких как парадокс Бурали-Форти, знаменитый парадокс Рассела, непосредственно отражались на исследованиях по логике ${ }^{11}$.

Философами, логиками и математиками осознается глубокая взаимная связь и обоюдная значимость математики и логики. Международные Конгрессы Математиков (ICM) и Международные Философские Конгрессы (IPhC) идут «рука об руку» до 1912 г.: II IPhC, III ICM (1904), III IPhC, IV ICM (1908), IV IPhC (1911), V ICM (1912). Затем тяжелый раскол в научное сообщество вносит мировая война 1914-1918 гг. и конгрессы прерываются надолго [49]. Несомненно, эта исключительная возможность взаимодействия и сотрудничества сильнейшим образом сказалась как на математике, так и на логике.

$$
* * *
$$

Труды некоторых логиков младшего поколения - например, Н.А. Васильева [9], И.Д. Менделеева (1883-1936) [32], [33], принадлежат, в некотором смысле, уже другой эпохе. В них очень сильно чувствуется отход от антропологической точки зрения. «Существенные изменения в содержание логики внесло и создание математической логики», - писал Н.А. Васильев [8, с. 122]. В своих работах он помимо отсылок к таким блестящим именам западноевропейских ученых, как Рассел, Пеано, Пуанкаре, Гильберт, Гамильтон, Больцано, Шлейермахер, Брентано, Лотц и др., цитирует российских логиков Порецкого, Каринского, Введенского.

И.Д. Менделеев также с одинаковой свободой ссылается как на математиков - Абеля, Грассмана, Гамильтона, логиков Буля, Шредера, Порецкого, так и на новейшие исследования, например, Гильберта, Пеано, Рассела, демонстрирует глубокое знание всех основных западных логико-математических работ своего времени. Практически избегая «технических» вопросов, характерных для работ по

\footnotetext{
${ }^{11}$ Бертран Рассел сообщил об открытом им парадоксе в письме известному логику Готтлобу Фреге. Обнаружение парадокса заставило Фреге отказаться от значительной части своих концепций. Сведения о парадоксе быстро распространились по научному сообщесту.
} 
математической логике (в том числе и Порецкого), И.Д. Менделеев показывает в то же время прекрасное понимание этих вопросов. В его книге обсуждается ряд идей, дальнейшее развитие которых сыграло большую роль в математической логике. Среди этих идей, например, идеи, получившие развитие в финитизме Гильберта: «Области не только опыта, но и естественно-научной теории есть области конечные» [33, с. 16]. «Этот метод (метод конечной математики. H.O., C.C.) <..> может быть сведен к одним логическим операциям» $[33$, с. 22$]$.

Менделеев критически относится к логицистам (таким как Фреге и Рассел), в значительной степени солидаризируясь с Пуанкаре, который был одним из провозвестников интуиционизма. Видны в работе Менделеева и предвестия исследований по непротиворечивости математических систем, занимавших центральное место в работах Гильберта, Тарского, Гёделя. «Все попытки доказательства непротиворечивости общих математических систем должны быть бесплодными» [33, с. 36]. Представление о широте его кругозора дают и ссылки в его публикациях на только что появившиеся в то время первые работы по квантовой механике.

Мы не ставим задачу оценить, внес ли Менделеев значительный вклад в развитие математических методов логики, несомненно, однако, что его подход и круг обсуждаемых им идей выглядят чрезвычайно современно. По существу, он принимает участие в профессиональной полемике, характерной и для последующих десятилетий.

$\mathrm{C}$ начала XX в. дискуссии приобретают особое распространение в академическом сообществе. Их усилению способствует ослабление цензурных ограничений после революции 1905-1907 гг. И Менделеев разворачивает полемику с Введенским на страницах своей книги «От критицизма к этической гносеологии. . . , задачи которой он видел в том, чтобы «с достаточной подробностью сопоставить свои выводы с выводами других современных систем» [33, с. V]. Как пишет автор, «выбор пал совершенно естественно на наиболее значительное философское произведение из появившихся в этом направлении в России, а именно на капитальное сочинение Проф. С.-П.Б. Ун. А.И. Введенского “Логика, как часть теории познания" (1912)» [33, с. V]. 
Говоря о научных дискуссиях, мы позволим себе ссылку на еще один пример критического разбора, который хронологически приближает нас к 1917 г., запустившему заметные перемены как в самом развитии науки логики, так и в стратегиях взаимодействия академического сообщества. И.И. Лапшин (1870-1952) уже в Петрограде публикует свою критику на диссертацию приват-доцента С.И. Поварнина (1870-1952) «Логика. Общее учение о доказательстве», которая понимается как попытка «в корне преобразовать всю систему логики» $[21$, с. 5], посвящая ее, к слову сказать, памяти «Профессора Платона Сергеевича Порецкого». Думается, что тема полемических стратегий в академическом сообществе того времени весьма плодотворная для более развернутого дальнейшего исследования, в том числе и сравнительного.

В статье рассмотрены вопросы формирования своего рода канонов коммуникации внутри российского сообщества логиков, различных видов публикационной активности, традиций ссылок на отечественных специалистов. Очевидно, что для научной коммуникации того времени печатные труды служат своего рода кафедрой как для острой полемики, так и для объединения в неформальные академические коалиции. В каком объеме возможно было следование этим традициям и канонам после революции 1917 года, как они менялись и насыщались, мы рассмотрим в следующих статьях.

\section{Список литературы}

[1] Андреев А.Ю. Русские студенты в немецких университетах XVIIIпервой половины XIX века. М.: Знак, 2005. 287 с.

[2] Анри B.A. Роль Лейбница в создании научных школ в России / / Успехи физических наук. 1999. Т. 169. № 12. С. 1329-1331.)

[3] Бажанов В.А. История логики в России и СССР. Концептуальный контекст университетской философии. М.:«Канон+», 2007. 336 с. 
[4] Бобров E.A. Генетическая логика // Сборник учебно-литературного общества при Императорском Юрьевском Университете. Тип. К. Маттисена, 1912. Т. 19. С. 61-80.

[5] Бобров E.А. Историческое введение в логику. Варшава: тип. Варш. учеб. округа, 1913. 140 с.

[6] Бобынин B.В. Опыты математического изложения логики // Физикоматематические науки в их настоящем и прошедшем. 1886. Вып. 1. $44 \mathrm{c}$.

[7] Бугаев Н.В. Числовые тождества, находящиеся в связи с свойствами символа // Соч. Николая Бугаева. М.: Унив. тип. (Катков и Кํ), 1866. 162 c.

[8] Василъев Н.А. Избр. тр. М.:«Наука», 1989. 263 с.

[9] Васильев Н.А. Логика и металогика // Логос. 1912-13. Кн. 1-2. С. 53-81.

[10] Введенский А.И. Логика, как часть теории познания. СПб.: С.-Петерб. высш. женские историко-ли. и юрид. курсы, 1909. 404 с.

[11] Владиславлев М.И. Логика. Обозрение индуктивных и дедуктивных приемов мышления и исторические очерки: логики Аристотеля, схоластической диалектики, логики формальной и индуктивной. СПб.: Тип. В. Демакова, 1872. 257 с.

[12] Грот Н. Я. К вопросу о реформе логики. Опыт новой теории умственных процессов. Нежин: Историко-филол. Ин-т, 1882. 350 с.

[13] Детская логика, сочиненная для употребления российского юношества. М.: Университет. тип. у Н. Новикова, 1787. 90 с.

[14] Инфельд Л. Эварист Галуа - Избранник богов / Пер. с англ. М. Кана. Изд. 3-е. М.: Молодая гвардия, 1965. 352 с.

[15] Каптерев П.Ф. История Логики. Лекции. Педагогические женские курсы 1879-1880 уч. г.. СПб.: Русская Литография Курочкина, 1880. 298 c.

[16] Каринский М.И. Логика. СПб.: Тип. Ф.Г. Елеонского и К., 1884-1885. 577 c.

[17] Карпов В.Н. Систематическое изложение логики. СПб.: тип. Я. Трея, 1856.314 c.

[18] Клайн М. Математика. Утрата определенности. М.: РИМИС, 2007. $640 \mathrm{c}$. 
[19] Краткая логика, или умословие, служащее в пользу Российскому Юношеству / Пер. с нем. М: Моск. Сенат. тип. иждивением А. Светушкина, 1788. 106 с.

[20] Ланге Н.Н. Учебник логики. Одесса: Е.П. Распопов, 1898. 238 с.

[21] Лапшин И.И. Гносеологические исследования // Логика отношений и силлогизм. Пг.: Сенат. тип., 1917. Вып. 1. 85 с.

[22] Лейкфельд П.Э. Различные направления в логике и основные задачи этой науки. Харьков: тип. Губерн. правления, 1890. 388 с.

[23] Лобачевский Н.И. Геометрические исследования по теории параллельных линий / Пер., коммент., вступит. ст. и примеч. проф. В.Ф. Кагана. М.-Л.: Изд. Академии Наук СССР, 1945. 176 с.

[24] Изотов Г.Е. Легенды и действительность в биографии Н.И. Лобачевского // Природа. 1993. № 7. С. 4-11.

[25] Логика: Биобиблиографический справочник (Россия-СССР-Россия). СПб.: Наука, 2001. 488 с.

[26] Бажанов B.A. Вступительная статья // Логико-гносеологическое направление в отечественной философии (первая половина XX века): М.И. Каринский, В.Н. Ивановский, Н.А. Васильев / Под ред. В.А. Бажанова. М.: РОССПЭН, 2012. С. 5-14.

[27] Бажанов B.A. Н.А. Васильев как человек и мыслитель. Открытие и судьба воображаемой логики // Логико-гносеологическое направление в отечественной философии (первая половина ХХ века): М.И. Каринский, В.Н. Ивановский, Н.А. Васильев / Под ред. В.А. Бажанова. М.: РОССПЭН, 2012. С. 267-408.

[28] Лодий П. Логические наставления, руководствующие к познанию и различению истинного от ложного. В пользу студентов СанктПетербургского Педагогического Института, сочиненные оного Института Ординарным Профессором, Словесных искусств и Философии Доктором, Коллежским Советником Петром Лодием. СПб.: Тип. Иос. Иоаннесова, 1815. 480 с.

[29] Лосский Н.О. Лекции по логике, читанные на 1 курсе Женского Педагогического института в 1903-1904 гг. СПб.: б.м., 1904. 354 с.

[30] Лосский Н.О. Сборник элементарных упражнений по логике. СПб.: тип. М.М. Стасюлевича, 1908. 206 с.

[31] Маковельский А.О. История логики. М.: Наука, 1967. 502 с. 
[32] Менделеев И.Д. Метод математики. Логика и гносеология математики. СПб.: Изд-во «Образование», 1913. 143 с.

[33] Менделеев И.Д От критицизма к этической гносеологии. Опровержение критицизма проф. А.И. Введенского. Введение в этическую гносеологию. Клин: Тип. бр. В. и Г. Лукошковых, 1914. 112 с.

[34] Мочульский Иван. Логика и риторика для дворян. М.: тип. Пономарева, 1789.7 с.

[35] Наука и кризисы. Историко-сравнительные очерки / Ред.-сост. Э.И. Колчинский. СПб.: Дмитрий Буланин, 2003. 1040 с.

[36] Новицкий О. Руководство к логике составленное ординарным проф. Универ. Св. Владимира Орестом Новицким. Киев: Унив. тип., 1841. 324 c.

[37] Порецкий П.С. Из области математической логики. М: т-во тип. А.И. Мамонтова, 1902. $21 \mathrm{c.}$

[38] Порецкий П.С. О способах решения логических равенств и об обратном способе математической логики. Казань: тип. В.М. Ключникова, 1884. $170 \mathrm{c}$.

[39] Радлов Э.Л. Логика. Лекции. СПб.: изд. М. Дабижа, 1880. 136 с.

[40] Райковский А.И. Логика, составленная протоиереем А. Райковским. Ч. 1. СПб.: Тип. И.И. Глазунова и К., 1857. 156 с.

[41] Рижский Иван. Умословие или умственная философия, написанная в С.-Петербургском горном училище в пользу обучающегося в нем юношества Иваном Рижским. СПб.: Тип. Горного Училища, 1790. 244 c.

[42] Рутковский Л.В. Основные типы умозаключений. СПб.: Типо-лит. А.Е. Ландау, 1888. 160 с.

[43] Светилин A.E. Конспект лекций по логике, читанных в СПб. Дух. Академии А.Е. Светилиным в 1881-1882. СПб., 1882. 433 с.

[44] Cmpуве Г. Е. Элементарная логика. Руководство для преподавания в средних учебных заведениях и для самообучения. Варшава: Тип. Газеты «Век», 1874. 149 с.

[45] Троицкий M.M. Учебник логики с подробными указаниями на историю этой науки в России и других странах. Изд. 2-е. М.: Тип. Э. Лисснера и Ю. Романа, 1886. 247 с. 
[46] Факчиолат И. Факчиолата Иакова. Логики, содержащий начала логические, в пользу обучающегося юношества / Пер. с латинского. М.: Тип. А. Решетникова, 1794. 262 с.

[47] Челпанов Г.И. Учебник логики (для гимназий и самообразования). Изд. 2-е. Киев-Одесса: И.А. Розов, 1906. 176 с.

[48] Ягодинский И.И. Генетический метод в логике. Казань: типо-лит. Император. Ун-та, 1909. 360 с.

[49] Albers D.J., Alexanderson G.L., Reid C. International Mathematical Congresses: An Illustrated History, 1893-1986. SpringerVerlag, 1987. 310 p.

[50] Compte Rendu du Deuxième Congrès International Des Mathématiciens, tenu à Paris du 6 à 12 aout $1900 / /$ Procès-verbaux et Communications publiés par E. Duporcq, Ingénieur des Télégraphes, Secrétaire général du Congrès. Paris: Gauthier-Villars, 1902. 456 p.

[51] Lobatschewsky N.I. Geometrische Untersuchungen zur Theorie der Parallellinien. Berlin: G. Fincke, 1840. 61 p.

[52] Pervouchine I.M. Concerning Arithmetical Operations Involving Large Numbers // Mathematical Papers Read at the International Mathematical Congress held in connection with the World's Columbian Exposition Chicago 1893 / Edited by the committee of the Congress: E. Hastings Moore, Oscar Bolza, Heinrich Maschke, Henry S. White. N.Y.: Macmillan and Co., 1896. 277 p.

[53] Poretsky P.S. Quelques lois ultérieures de la théorie des égalités logiques. Казань: типо-литография имп. ун-та, 1902. 163 с.

[54] Poretsky P.S. Sept lois fondamentales de la théorie des égalités logiques. Казань: типо-литография имп. ун-та, 1899. 157 с.

[55] Poretsky P.S. Exposé élémentaire de la théorie des égalités logiques à deux termes a et b // Revue de Métaphysique et de Morale. 1900. P. 169-188.

[56] Poretsky P.S. Théorie des égalités logiques à trois termes // Bibilothèque du Congrès International de Philosophie, III. Paris: Librairie Armand Colin, 1901. P. 201-235.

[57] Revue de Métaphysique et de Morale. 1900. Vol. 8. № 5. P. 503-698.

[58] Scott Ch. A. The International Congress of Mathematicians in Paris // Bulletin of the American Mathematical Society. 1900. Vol. 7(2). P. 57-79.

[59] Soulié $S$. La Revue de métaphysique et de morale et les congrès internationaux de philosophie (1900-1914): une contribution à 
la construction d'une Internationale philosophique // Revue de métaphysique et de morale. 2014. Vol. 84(4). P. 467-481

[60] Verhandlungen der ersten internationalen Mathematiker-Kongresses in Zürich vom 9 bis 11. August 1897 / Herausgegeben von Dr. Ferdinand Rudio professor am eidgenössischen Polytechnikum. Leipzig: Druck und Verlag von B.G. Teubner, 1898. 320 p. 


\title{
N.Kh. Orlova, S.V. Soloviev \\ On the History of Logic in Russia Before Revolution: Strategies of Academic Interaction
}

\author{
Orlova Nadezhda Khadjimerzanovna \\ Institute of Philosophy, Saint Petersburg State University \\ 5 Mendeleevskaya Liniya, St. Petersburg, 199034, Russian Federation \\ e-mail: nadinor@mail.ru
}

\author{
Soloviev Sergei Vladimirovich \\ University of Toulouse \\ Toulouse 118 route de Narbonne, 31062, France \\ Saint Petersburg National Research University of Information Technologies, \\ Mechanics and Optics \\ 49 Kronverksky pr., Saint-Petersburg, 197101, Russian Federation \\ e-mail: soloviev@irit.fr
}

Some questions of emergence and development of logical studies in Russia before Revolution are considered from the point of view of communication between scholars. A historical retrospective is reconstructed, that includes the peculiar canon applied to the educational literature in logic, the first steps of the tradition of scientific references, the practice to publish critical books in answer to publications by colleagues. Different kinds of publications are considered (translations, textbooks, monographs etc.) For Russian logicians books were a space for discussion and exchange, also with international scientific community. The interaction with other sciences such as psychology and mathematics, and gradual emancipation of logic are outlines. In particular it is considered the influence on the development of Russian logic of so called revolution in mathematics. The paper is based on multiple sources never reprinted after original publication

Keywords: Vasiliev history of logic, mathematics, academic community, strategies of communication, publication activity, referencing

\section{References}

[1] Andreev, A.Yu. Russkie studenty v nemetskikh universitetakh XVIIIpervoi poloviny XIX veka [Russian students in German universities of XVIII-first half of XIX century]. Moscow: Znak Publ., 2005. 287 p. (In Russian) 
[2] Anri, V.A. "Rol' Leibnitsa v sozdanii nauchnykh shkol v Rossii" [The role of Leibnitz in the establishment of scientific schools in Russia], Uspekhi fizicheskikh nauk. 1999, Vol. 169, No. 12, pp. 1329-1331. (In Russian)

[3] Bazhanov, V.A. Istoriya logiki v Rossii i SSSR. Kontseptual'nyi kontekst universitetskoi filosofii [History of logic in Russia and USSR. Conceptual context of university philosophy]. Moscow: Kanon+ Publ., 2007. 336 p. (In Russian)

[4] Bobrov, E.A. "Geneticheskaya logika" [Genetic logic], Sbornik uchebnoliteraturnogo obshchestva pri Imperatorskom Yur'evskom Universitete [Collected papers of the educational-literary society at the Emperor's Yur'ev University], Vol. 19. K. Mattisen printing press, 1912, pp. 61-80. (In Russian)

[5] Bobrov, E.A. Istoricheskoe vvedenie v logiku [A historical introduction to logic]. Warsaw: printing press of the Warsaw's school district, 1913. 140 pp. (In Russian)

[6] Bobynin, V.V. "Opyty matematicheskogo izlozheniya logiki" [Essays of mathematical exposition of logic], Physico-mathematical sciences in their present and past, Issue 1. Printing press of A.I. Mamontov and Co., 1886. 44 pp. (In Russian)

[7] Bugaev, N.V. "Chislovye tozhdestva, nakhodyashchiesya v svyazi s svoistvami simvola" [The Numerical identities which are in connection with properties of a symbol], Sochineniya Nikolaya Bugaeva [Collected papers of Nikolya Bugaev]. Moscow: Univ. a type. (Katkov and $\mathrm{K}^{\circ}$ ), 1866. 162 pp. (In Russian)

[8] Vasil'ev, N.A. Izbrannye trudy [Selected works]. Moscow: Science Publ., 1989. 263 pp. (In Russian)

[9] Vasil'ev, N.A. "Logika i metalogika" [Logic and metalogic], Logos, 19121913, Vol. 1-2, pp. 53-81. (In Russian)

[10] Vvedenskii, A.I. Logika, kak chast' teorii poznaniya [Logic as part of the theory of knowledge]. Saint-Petersburg: S.-Peterb. higher historicoliterary and law courses for women Publ., 1909. 404 pp. (In Russian)

[11] Vladislavlev, M.I. Logika. Obozrenie induktivnykh i deduktivnykh priemov myshleniya $i$ istoricheskie ocherki: logiki Aristotelya, skholasticheskoi dialektiki, logiki formal'noi i induktivnoi [Logic. A survey of inductive and deductive methods of thought and historical outlines: of the logic of Aristotle, scholastic dialectic, formal and inductive logic]. Saint-Petersburg: V. Demakov's printing press, 1872. 257 pp. (In Russian) 
[12] Grot, N.Ya. K voprosu o reforme logiki. Opyt novoi teorii umstvennykh protsessov [On the issue of a reform of logic. An essay of new theory of mental processes]. Nezhin: Historico-philological Institute Publ., 1882. 350 pp. (In Russian)

[13] Detskaya logika, sochinennaya dlya upotrebleniya rossiiskogo yunoshestva [Child's logic, composed for use by Russian youth]. Moscow: N. Novikov's university printing press, 1787.90 pp. (In Russian)

[14] Infel'd, L. Evarist Galua - Izbrannik bogov [Whom the gods love. The story of Evariste Galois], trans. by M. Kan. Moscow: Molodaya gvardiya Publ., 1965. 352 pp. (In Russian)

[15] Kapterev, P.F. Istoriya Logiki. Lektsii. Pedagogicheskie zhenskie kursy 1879-1880 uch.g. [History of logic. Lectures. Pedagogical courses for women. Year 1879-1880]. St.-Petersburg: Kurochkin's Russian Lithography, 1880. 298 pp. (In Russian)

[16] Karinskii, M. I. Klassifikatsiya vyvodov [Classification of deductions]. St.-Petersburg: printing press of F.G. Eleonsky and Co., 1880. 577 pp. (In Russian)

[17] Karpov, V.N. Sistematicheskoe izlozhenie logiki [A systematic exposition of logic]. St.-Petersburg: printing press of Ya. Trey, 1856. 314 pp. (In Russian)

[18] Kline, M. Matematika. Utrata opredelennosti [Mathematics. The loss of certainty]. Moscow: RIMIS Publ., 2007. 640 pp. (In Russian)

[19] Kratkaya logika, ili umoslovie, sluzhashchee v pol'zu Rossiiskomu Yunoshestvu. Perevedena s nemetskogo yazyka [Precis of logic, or reasoning, to be employed to the good of Russian youth. Translated from German]. Moscow: the Senate printing press on the expense of A. Svetushkin, 1788. 106 pp. (In Russian)

[20] Lange, N.N. Uchebnik logiki [Textbook of logic]. Odessa: E.P. Raspopov Publ., 1898. 238 pp. (In Russian)

[21] Lapshin, I.I. "Gnoseologicheskie issledovaniya" [Gnoseological studies], Logika otnoshenii $i$ sillogizm. Petrograd: Senate printing press, 1917. Issue 1. 85 pp. (In Russian)

[22] Leikfel'd, P.E. Razlichnye napravleniya $v$ logike $i$ osnovnye zadachi eto $i$ nauki [Different trends in logic and main problems of this science]. Khar'kov: printing press of Governor's office, 1890. 388 pp. (In Russian)

[23] Lobachevskii, N.I. Geometricheskie issledovaniya po teorii parallel'nykh linii. Perevod, kommentarii, vstupitel'nye stat'i $i$ primechaniya professora 
V.F. Kagana [Geometrical investigations on the theory of parallel lines. Translation, comments, introductory papers and notes by V.F. Kagan]. Moscow-Leningrad: Academy of Sciences of the USSR Publ., 1945. 176 pp. (In Russian)

[24] Izotov, G.E. "Legendy i deistvitel'nost' v biografii N.I. Lobachevskogo" [Legends and reality in the biography of N.I. Lobachevsky], Priroda, 1993, No. 7, pp. 4-11. (In Russian)

[25] Logika: Biobibliograficheskii spravochnik (Rossiya-SSSR-Rossiya) [Logic. A biobibliographical directory. (Russia-USSR-Russia)]. St.-Petersburg: Science Publ., 2001. 488 pp. (In Russian)

[26] Bazhanov, V.A. "Vstupitel'naya stat'ya" [Introductory paper], Logikognoseologicheskoe napravlenie $v$ otechestvennoi filosofii (pervaya polovina $X X$ veka): M.I. Karinskii, V.N. Ivanovskii, N.A. Vasil'ev [The logicognoseological direction in Russian philosophy (first half of XX century): M.I. Karinskii, V.N. Ivanovskii, N.A. Vasil'ev ], ed. by V.A. Bazhanov. Moscow: ROSSPEN Publ., 2012, pp. 5-14. (In Russian)

[27] Bazhanov, V.A. "N.A. Vasil'ev kak chelovek i myslitel'. Otkrytie i sud'ba voobrazhaemoi logiki" [N.A. Vasil'ev as a man and thinker. Discovery and destiny of imaginary logic], Logiko-gnoseologicheskoe napravlenie $v$ otechestvennoi filosofii (pervaya polovina XX veka): M.I. Karinskii, V.N. Ivanovskii, N.A. Vasil'ev [The logico-gnoseological direction in Russian philosophy (first half of XX century): M.I. Karinskii, V.N. Ivanovskii, N.A. Vasil'ev], ed. by V.A. Bazhanov. Moscow: ROSSPEN Publ., 2012, pp. 267-408. (In Russian)

[28] Lodii, P. Logicheskie nastavleniya, rukovodstvuyushchie $k$ poznaniyu i razlicheniyu istinnogo ot lozhnogo. V pol'zu studentov Sankt-Peterburgskogo Pedagogicheskogo Instituta, sochinennye onogo Instituta Ordinarnym Professorom, Slovesnykh iskusstv i Filosofii Doktorom, Kollezhskim Sovetnikom Petrom Lodiem [Logical instructions, directing to understanding and discerning the true and the false. To the good of the students of Saint-Petersburg Pedagogical Instititute, composed by the ordinary professor, doctor of rhetoric and philosophy, collegiate councillor Petr Lodii]. St.-Petersburg.: printing press of Ios. Ioannesov, 1815. 480 pp. (In Russian)

[29] Losskii, N.O. Lektsii po logike, chitannye na 1 kurse Zhenskogo Pedagogicheskogo instituta $v$ 1903-1904 gg. [Lectures on logic given to the 1st year of the Pedagogical Institute for Women in 1903-1904]. St.-Petersburg, 1904. 354 pp. (In Russian) 
[30] Losskii, N.O. Sbornik elementarnykh uprazhnenii po logike [Collection of elementary exercises in logic]. St.-Petersburg: printing press of M.M. Stasyulevich, 1908. 206 pp. (In Russian)

[31] Makovel'skii, A.O. Istoriya logiki [History of logic]. Moscow: Science Publ., 1967. 502 pp. (In Russian)

[32] Mendeleev, I.D. Metod matematiki. Logika i gnoseologiya matematiki [Method of mathematics. Logic and gnoseology of mathematics]. St.Petersburg: Obrazovanie Publ., 1913. 143 pp. (In Russian)

[33] Mendeleev, I.D. Ot krititsizma $k$ eticheskoi gnoseologii. Oproverzhenie krititsizma prof. A.I. Vvedenskogo. Vvedenie v eticheskuyu gnoseologiyu [From criticism to ethical gnoseology. A refutation of the criticism by prof. A. I. Vvedensky. Introduction to ethical gnoseology]. Klin: printing press of br.V. and G. Lukoshkov, 1914. 112 pp. (In Russian)

[34] Mochul'skii, Ivan. Logika i ritorika dlya dvoryan [Logic and rhetoric for noblemen]. Moscow: Ponomarev's printing press, 1789. 71 pp. (In Russian)

[35] Nauka $i$ krizisy. Istoriko-sravnitel'nye ocherki [Science and Crises. Historico-comparative essays], ed. by E.I. Kolchinskii. St.-Petersburg: Dmitrii Bulanin Publ., 2003. 1040 pp. (In Russian)

[36] Novitskii, O. Rukovodstvo k logike sostavlennoe ordinarnym prof. Univer. Sv. Vladimira Orestom Novitskim [Instruction in logic composed by ordinary professor of St. Vladimir University Orest Novitsky]. Kiev: university printing press, 1841. 324 pp. (In Russian)

[37] Poretskii, P.S. Iz oblasti matematicheskoi logiki [From the domain of mathematical logic], M: partnership of A.I. Mamontov's printing press, 1902. 21 pp. (In Russian)

[38] Poretskii, P.S. O sposobakh resheniya logicheskikh ravenstv $i$ ob obratnom sposobe matematicheskoi logiki [On methods of solution of logical equalities and on inverse method in mathematical logic]. Kazan': V.M. Klyuchnikov's printing press, 1884.170 pp. (In Russian)

[39] Radlov, E.L. Logika. Lektsii [Logic. Lectures]. St.-Petersburg: M. Dabizh Publ., 1880. 136 pp. (In Russian)

[40] Raikovskii, A.I. Logika, sostavlennaya protoiereem A. Raikovskim [Logic, composed by archpriest A. Raikovsky]. Pt.1, St.-Petersburg: I.I. Glazunov and Co. printing press, 1857. 156 pp. (In Russian)

[41] Rizhskii, I. Umoslovie ili umstvennaya filosofiya, napisannaya $v$ S.Peterburgskom gornom uchilishche $v$ pol'zu obuchayushchegosya $v$ nem 
yunoshestva Ivanom Rizhskim [Reasoning or mental philosophy, written at St. Petersburg mining school to the good of youth that study there by Ivan Rizhsky]. St.-Petersburg: Mining school's press, 1790. 244 pp. (In Russian)

[42] Rutkovskii, L.V. Osnovnye tipy umozaklyuchenii [Main types of reasoning]. St.-Petersburg: press and lithography of A.E. Landau, 1888. 160 pp. (In Russian)

[43] Svetilin, A.E. Konspekt lektsii po logike, chitannykh $v$ SPb. Dukh. Akademii A.E. Svetilinym $v$ 1881-1882 [Lecture notes in logic, read at $\mathrm{SPb}$ Theological Academy by A.E. Svetilin in 1881-1882]. St.-Petersburg, 1882. 433 pp. (In Russian)

[44] Struve, G.E. Elementarnaya logika. Rukovodstvo dlya prepodavaniya $v$ srednikh uchebnykh zavedeniyakh $i$ dlya samoobucheniya [Elementary logic. Instrucion for teaching at secondary educational institutions and for self-education]. Warsaw: newspaper "Vek" printing press (I. Nikovsky), 1900. 149 pp. (In Russian)

[45] Troitskii, M.M. Uchebnik logiki s podrobnymi ukazaniyami na istoriyu etoi nauki $v$ Rossii $i$ drugikh stranakh [Textbook in logic with detailed notes on history of this science in Russia and other countries], 2nd ed. Moscow: E. Lissner's and Yu. Roman's press, 1886. 247 pp. (In Russian)

[46] Fakchiolat, I. Fakchiolata Iakova Logiki, soderzhashchie nachala logicheskie, v pol'zu obuchayushchegosya yunoshestva. Per. s latinskogo [Iakov Fakchiolat's Logic, including basics of logic, to the good of student youth. Transl. from Latin]. Moscow: printing press of A. Reshetnikov, 1794. 262 pp. (In Russian)

[47] Chelpanov, G.I. Uchebnik logiki (dlya gimnazii i samoobrazovaniya) [Textbook in logic (for gymnasium and self-education)], 2nd ed. Kiev-Odessa: I. A. Rozov Publ., 1906. 176 pp. (In Russian)

[48] Yagodinskii, I.I. Geneticheskii metod v logike [Genetic method in logic]. Kazan': Emperor's university printing press and lithography, 1909. 360 pp. (In Russian)

[49] Albers, D.J., Alexanderson, G.L., Reid, C. International Mathematical Congresses: An Illustrated History, 1893-1986. SpringerVerlag, 1987. 310 pp.

[50] "Compte Rendu du Deuxième Congrès International Des Mathématiciens, tenu à Paris du 6 à 12 aout 1900" [Official Report of the Second International Congress Of Mathematicians, held in Paris from 6 to $12 \mathrm{Au}-$ 
On the History of Logic in Russia Before Revolution: Strategies ...

gust 1900], Procès-verbaux et Communications publiés par E. Duporcq, Ingénieur des Télégraphes, Secrétaire général du Congrès [Minutes and Communications published by E. Duporcq Engineer Telegraph, General Secretary of the Congress]. Paris: Gauthier-Villars, 1902. 456 pp. (In French)

[51] Lobatschewsky, N.I. Geometrische Untersuchungen zur Theorie der Parallellinien [Geometric Investigations on the theory of parallel lines]. Berlin: G. Fincke, 1840. 61 pp. (In German)

[52] Pervouchine, I.M. "Concerning Arithmetical Operations Involving Large Numbers", Mathematical Papers Read at the International Mathematical Congress held in connection with the World's Columbian Exposition Chicago 1893, ed. by the committee of the Congress: E. Hastings Moore, Oscar Bolza, Heinrich Maschke, Henry S. White. New York: Macmillan and Co. 1896. 277 pp.

[53] Poretsky, P.S. Quelques lois ultérieures de la théorie des égalités logiques [Some subsequent laws of logic equations theory]. Kazan': Emperor's university printing press and lithography, 1902. 163 pp. (In French)

[54] Poretsky P.S. Sept lois fondamentales de la théorie des égalités logiques [September fundamental laws of logic equations theory]. Kazan: Emperor's university printing press and lithography, 1899, 157 pp. (In French)

[55] Poretsky, P.S. "Exposé élémentaire de la théorie des égalités logiques à deux termes a et b" [Elementary of logical theory equations with two terms a and b Presentation], Revue de Métaphysique et de Morale, 1900, pp. 169-188. (In French)

[56] Poretsky, P.S. "Théorie des égalités logiques à trois termes" [Theory of logical equations in three words], Bibilothèque du Congrès International de Philosophie, III. Paris: Librairie Armand Colin, 1901, pp. 201-235. (In French)

[57] Revue de Métaphysique et de Morale [Review of Metaphysics and Moral], 1900, Vol. 8, No. 5, pp. 503-698. (In French)

[58] Scott, Ch.A. "The International Congress of Mathematicians in Paris", Bulletin of the American Mathematical Society, 1900, Vol. 7(2), pp. 57-79.

[59] Soulié, S. "La Revue de métaphysique et de morale et les congrès internationaux de philosophie (1900-1914): une contribution à la construction d'une Internationale philosophique" [Metaphysical Journal and morality and international Congress of Philosophy (1900-1914): a contribution to 
the construction of a philosophical International], Revue de métaphysique et de morale, 2014, Vol. 84(4), pp. 467-481. (In French)

[60] Verhandlungen der ersten internationalen Mathematiker-Kongresses in Zürich vom 9 bis 11. August 1897 [Negotiations of the first international Congress of Mathematicians in Zurich from 9 to 11 August 1897], herausgegeben von Dr. Ferdinand Rudio professor am eidgenössischen Polytechnikum. Leipzig: Druck und Verlag von B.G. Teubner, 1898. 320 pp. (In German) 


\section{Information for authors}

- Logical Investigations accepts for submission papers containing original results in all areas of logic. The papers should not have been published or simultaneously submitted to another publication. (Sections of the journal: http://eng.iph.ras.ru/log_inv.htm)

- The Editor in Chief makes the decision which of the submitted articles should be published, with due account for opinions of the Editorial Board and the reviewers. The decision is made within two months since the date of submission of the manuscript.

- Authors are not charged for the publication.

- Papers should be submitted electronically in the $\operatorname{LT}_{\mathrm{E} X} 2_{\varepsilon}$ format (special permission of the editorial board is needed for submissions to be made in the MS Word format). While typesetting a paper, the style file li.sty and the master file li.tex should be used; both files, along with a sample paper file, can be accessed at http://eng.iph.ras.ru/page49940199.htm

- Papers should not exceed 24 pages in the above mentioned format (including the notes, the bibliography, the abstract).

- Footnotes should appear at the bottom of the page and should be numbered sequentially throughout the paper.

- In addition to the principal text, the manuscript should include the following mandatory elements:

1) Information about the author(s):

- first and last names of the author;

- affiliation;

- full address of the place of work (including the postal code, country and city);

- author's e-mail address.

2) abstract (100 to 200 words);

3) keywords (5-7 words/word combinations);

4) the list of works cited.

- The bibliographical references should be placed at the end of the paper as the general list ordered alphabetically, and formatted in strict accordance with the guidelines of the international bibliographical databases (Scopus and others). Please see the guidelines here: http://eng.iph.ras.ru/page49940199.htm

Submissions should be e-mailed to the following address:

logicalinvestigations@gmail.com 